\title{
REFLEXIONES SOBRE EL CONCEPTO INTERNACIONAL DE PATRIMONIO ARQUEOLÓGICO
}

REFLECTIONS ON THE CONCEPT OF

ARCHAEOLOGICAL INTERNATIONAL HERITAGE

\section{RESUMEN}

El Patrimonio Arqueológico ha experimentado a lo largo de los siglos XIX y XX un proceso de cambio ligado a trascendentales acontecimientos políticos como las dos guerras mundiales. De una visión coleccionista se ha pasado a entenderse como un valor social. Tomando como base algunos de los documentos internacionales más importantes y analizando cada uno de ellos, se llega a la conclusión de que estamos ante un problema lejos de estar resuelto por la dificultad de uniformar conceptos culturales en una sociedad globalizada y diversificada.

Palabra clave: Patrimonio Cultural, Arqueología, Legislación Internacional, Globalización

\begin{abstract}
The archeological heritage has experienced a process of change trough the XIX and XX centuries linked to transcendental political events such as two world wars. From a collector's perspective it has come to be understood as a social value. Taking as base some of the most important international documents and analyzing each of them, we conclude that we are facing a problem that is far from being solved because of the difficulty of unifying cultural concepts in a globalized and diversified society.
\end{abstract}

Keywords: Cultural Heritage, Archaeology, International Law, Globalization 


\section{INTRODUCCIÓN}

El Patrimonio Arqueológico, entendido como conjunto de los bienes materiales susceptibles de ser estudiados con metodología arqueológica, ha sido tradicionalmente ligado al concepto de Patrimonio Cultural por lo que los cambios conceptuales producidos en este último, necesariamente han influido en la concepción que del Patrimonio Arqueológico (en adelante PA) tenemos.

Sin embargo, la sociedad actual viene demandando sistemáticamente que el PA sea protegido y estudiado acorde con una metodología moderna y libre de los prejuicios de siglos anteriores. Por tanto, es normal que los organismos encargados de ello a nivel mundial (en especial la UNESCO), promuevan encuentros y disposiciones relativas a una cierta uniformidad en cuanto al concepto y metodología de estudio de dicho Patrimonio (INCP 2007).

A lo largo del siglo XX han tenido lugar una serie de reuniones que han tratado distintos aspectos referentes al Patrimonio Cultural y Arqueológico lo cual ha generado un enorme volumen de documentación que a veces ha pasado desapercibido porque no dejan de ser recomendaciones que la mayoría de los casos los distintos legisladores no tienen en cuenta a la hora de uniformar criterios globales.

En estas convenciones se ha tratado de llegar a consensos difíciles de conseguir debido, qué duda cabe, a las profundas diferencias en lo que debe entenderse por Patrimonio Cultural y, para el caso que nos ocupa, el $\mathrm{Pa}$ trimonio Arqueológico. Para ello, el presente estudio, realiza una reflexión sobre el propio concepto de PA y ver algunos ejemplos en legislaciones actuales.

\section{METODOLOGÍA}

En el presente estudio, se han analizado en profundidad las leyes española y andaluza vigentes sobre Patrimonio Arqueológico: la Ley 16/1985 de 25 de junio del Patrimonio Histórico Español y la Ley 14/2007 de 26 de noviembre de Patrimonio Histórico de Andalucía. A su vez, se ha comparado con lo que es considerado como Patrimonio Arqueológico por las legislaciones internacionales, como la carta de Atenas (1931), el convenio de La Haya (1954), la Carta de Quito (1967) o la Carta Internacional para la Gestión del Patrimonio Arqueológico (1990). Por último, el Convenio Europeo sobre la Protección del Patrimonio Arqueológico (1992), define al Patrimonio Arqueológico como el que está formado no solo por un conjunto de bienes (muebles e inmuebles) independientemente de la procedencia y estudiados con metodología científica, sino que a este concepto se le suma el de su contexto.

\section{RESULTADOS Y DISCUSIÓN}

\section{Evolución del concepto de Patrimonio Ar- queológico}

Para la mayoría de legislaciones (pongo por ejemplo el caso de la española y de la andaluza), el Patrimonio Arqueológico (PA) es un conjunto de bienes tanto muebles como inmuebles en los que se destaca por encima de todo, que la metodología a aplicar en su estudio sea la arqueológica. Así, el art. 40.1 de la Ley 16/1985 de 25 de junio del Patrimonio Histórico Español estipula que:

Conforme a lo dispuesto en el artículo $1^{\circ}$ de esta Ley, forman parte del Patrimonio Histórico Español los bienes muebles o inmuebles de carácter histórico susceptibles de ser estudiados con metodología arqueológica, hayan sido o no extraídos y tanto si se encuentran en la superficie o en el subsuelo, en el mar territorial o en la plataforma continental. Forman parte, asimismo, de este Patrimonio los elementos 
geológicos y paleontológicos relacionados con la historia del hombre y sus orígenes y antecedentes. 2. Quedan declarados Bienes de Interés Cultural por ministerio de esta Ley las cuevas, abrigos y lugares que contengan manifestaciones de arte rupestre. (Ley 16/1985 de 25 de junio del Patrimonio Histórico Español).

Por su parte, la Ley 14/2007 de 26 de noviembre de Patrimonio Histórico de Andalucía se hace eco de esta misma reflexión al estipular en su art. 47:

Forman parte del Patrimonio Arqueológico los bienes muebles o inmuebles de interés histórico, susceptibles de ser estudiados con metodología arqueológica, hayan sido o no extraídos y tanto si se encuentran en la superficie o en el subsuelo, en las aguas interiores, en el mar territorial o en la plataforma continental. Asimismo, forman parte de este Patrimonio los elementos geológicos y paleontológicos relacionados con la historia de la humanidad y sus orígenes y antecedentes. (Ley 14/2007 de 26 de noviembre de $\mathrm{Pa}$ trimonio Histórico de Andalucía).

Vemos pues que el concepto de PA va íntimamente ligado a la metodología de estudio empleada y no tanto a la antigüedad del bien. Así, formará parte del PA tanto un bifaz del Paleolítico Inferior como una nave industrial del siglo XVIII siempre que la metodología empleada en su estudio sea la arqueológica.

Es un concepto bastante amplio y poco definido que puede llevar a situaciones controvertidas pues ¿Formarían parte del PA los cadáveres de represaliados de la guerra civil española de 1936/39 depositados en fosas comunes? ¿O solamente tomamos como sujeto los bienes muebles e inmuebles, esto es, la cultura material? Son problemas que el legislador debe definir para evitar situaciones controvertidas.

Ciñéndonos a la definición, junto al estudio con metodología arqueológica, la otra ca- racterística es que haya un interés histórico. Aquí surge otro problema porque el concepto de interés histórico ha ido evolucionando a lo largo del tiempo, del puramente histórico-artístico del siglo XIX y primera mitad del XX hasta las corrientes más actuales producto de la influencia de la dialéctica marxista a partir de la segunda mitad del siglo $\mathrm{XX}$.

Estamos pues ante un concepto que debe desgajarse todavía de esa influencia de la cultura occidental, tradicionalmente más materialista y menos social, donde prima el objeto sobre el contexto. No cabe duda que las legislaciones actuales, como la ley andaluza de 2007, presentan al PA como un patrimonio más integrado en la sociedad, pero qué duda cabe que quedan todavía muchas cuestiones por resolver, en especial la de desligar la relevancia material del concepto y hacerlo mucho más social. Veamos algunos textos sobre el Patrimonio Arqueológico en el ámbito internacional

Moviéndonos en un ámbito supranacional, el PA cuenta con innumerables problemas de concepto. A nadie se le escapa que, en un mundo tan diverso, no puede existir un concepto uniforme de PA. Tradicionalmente el PA ha sido definido desde una óptica meramente occidental donde prima lo material y, dentro de ésta, lo arquitectónico, monumental o estético. Inconscientemente pensamos que un edificio de la Grecia clásica como el Templo de Poseidón en Paestum (figura 1) es indudablemente PA pero podremos mostrar nuestras reservas sobre una estructura histórica realizada con la técnica del Bahareque en la región de los Andes si no conocemos su contexto arquitectónico.

Es por esto que, desde la promulgación en 1931 de la Carta de Atenas, los diversos organismos internacionales se han ocupado de definir y dar soluciones más o menos consensuadas al problema que suscita la conceptualización del PA. La Carta de Atenas muestra la preocupación por los monumentos "de Arte e Historia" de los Estados fir- 
Figura 1.- Paestum (Italia). Templo de Poseidón.

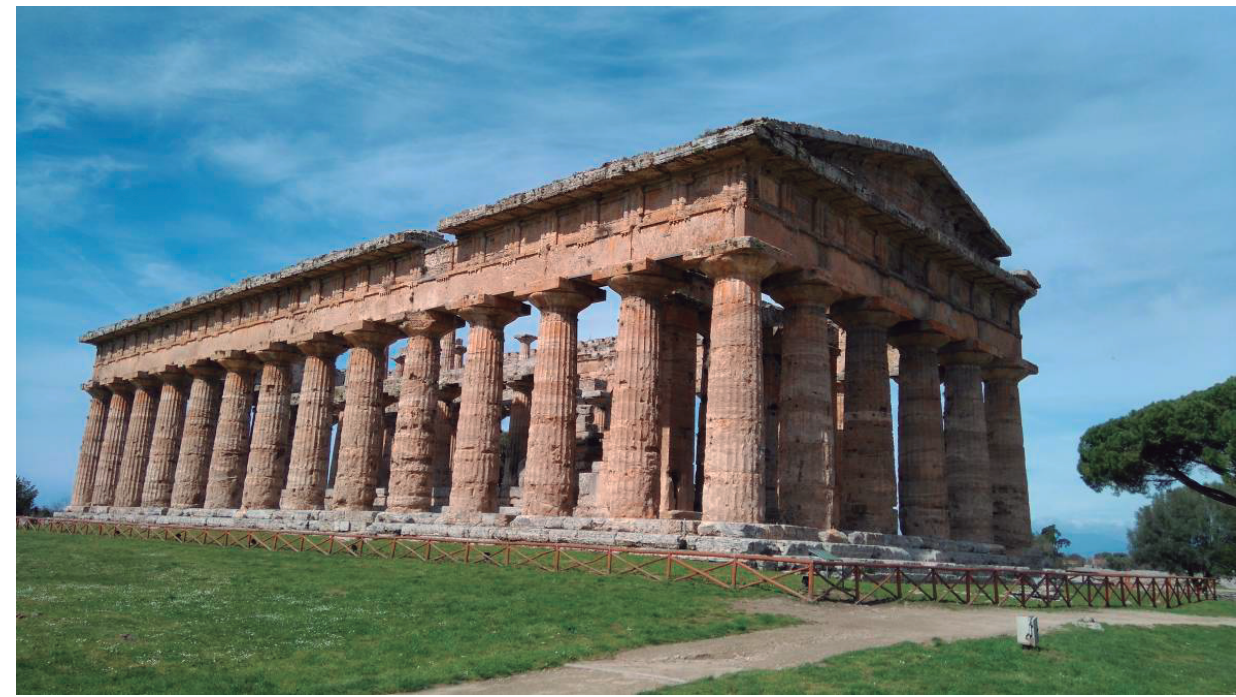

Fuente: Elaboración propia

mantes ante las desastrosas consecuencias que la Primera Guerra Mundial causó en el territorio europeo. Se convino que, sin tener ningún tipo de vinculación, los firmantes procurarían la salvaguarda de los monumentos artísticos y arqueológicos.

Evidentemente esto no funcionó y hubo que llegar a una destrucción casi total de Europa tras la Segunda Guerra Mundial para que, al amparo de las Naciones Unidas por medio de la UNESCO, los Estados se comprometieran a la salvaguarda del PA.

El Convenio de La Haya de 1954 sobre Protección de Bienes Culturales en caso de Conflicto Armado es buena prueba de ello, aunque ante la indefinición y poca uniformidad del concepto de bien cultural en los diferentes Estados, esta declaración no pasó de ser meramente idealista y siempre dentro de una órbita del mundo occidental y europeo.

La preocupación de la UNESCO por el PA tiene su arranque en la reunión celebrada en Nueva Delhi del 5 de noviembre al 5 de diciembre de 1956 donde se dictó la Recomendación que define los Principios Internacionales que deberán aplicarse a las Excavaciones Arqueológicas.

Lo primero que llama la atención es que invita a los países a que incorporen a sus legis- laciones las recomendaciones acordadas en vista de un intento de uniformidad cultural imposible. Define las excavaciones arqueológicas en su art. 1 como "aquellas investigaciones que tengan por finalidad el descubrimiento de objetos de carácter arqueológico, tanto en el caso de que dichas investigaciones entrañen una excavación del suelo o una exploración sistemática de la superficie...". (INCP 2007:315)

Sin mencionar para nada la metodología a emplear que, como vimos anteriormente, es condición indispensable en las legislaciones más modernas, por primera vez acuña el término de Patrimonio Arqueológico aunque sin definirlo, al dictar los Principios Generales, recomendando en su art. 4 que "Cada Estado Miembro debería asegurar la protección de su Patrimonio Arqueológico, tomando particularmente en consideración los problemas planteados por las excavaciones arqueológicas y de acuerdo con disposiciones de la presente recomendación". (INCP 2007:318)

No obstante, promulga una cuestión esencial, a mi entender, en un intento de lograr una cierta uniformidad en lo concerniente al PA. Me refiero a la redacción del art. 6 dedicado al órgano de protección de las excavaciones arqueológicas. 
Si bien la diversidad de tradiciones y las desigualdades de recursos se oponen a que todos los Estados Miembros adopten un sistema de organización uniforme de los servicios administrativos encargados de las excavaciones arqueológicas, existen, sin embargo, ciertos principios que deberían ser comunes a todos los servicios nacionales: a) El servicio encargado de las excavaciones arqueológicas debería ser, en la medida de lo posible, un organismo de la administración central del Estado, o por lo menos una organización que, en virtud de una ley, dispusiera de medios que le permitieran llegado el caso tomar las medidas urgentes que sean necesarias. Ese servicio, encargado de la administración general de las actividades arqueológicas, debería facilitar, en colaboración con los institutos de investigación y las universidades, la enseñanza de las técnicas de las excavaciones arqueológicas. Este servicio debería preparar también una documentación centralizada, con los planos correspondientes, acerca de los monumentos a su cargo, muebles e inmuebles, así como una documentación relativa a cada museo importante, a los archivos cerámicos, iconográficos, etc. b) Debería asegurarse la continuidad de los recursos financieros, en especial para lograr: i) el buen funcionamiento de los servicios; ii) la ejecución de un plan de trabajos adecuado a la riqueza arqueológica del país, comprendidas las publicaciones científicas; iii) la fiscalización de los descubrimientos fortuitos; iv) el mantenimiento de las excavaciones y monumentos. (INCP 2007:319)

Es un artículo largo pero bastante claro, señala en primer lugar que la diversidad de tradiciones (¿conceptos?) y recursos impiden una uniformidad a la hora de acometer la gestión del PA pero recomienda una serie de principios que en suma se resumen en que debe ser el Estado el encargado de la autorización y administración de las excavaciones arqueológicas; también debe asegurarse la continuidad de los recursos financieros para llevar a cabo un buen plan de gestión.

En definitiva, como sostienen María Ángeles Querol y Belén Martínez (Querol y Martínez 1996:296; Querol 2010:201), la recomendación es producto del ambiente de Guerra Fría vivida en el mundo a partir de la década de los cincuenta del siglo pasado y los intentos de la UNESCO por promover la paz mundial a través de la cooperación cultural. La concepción casi feudal del PA en manos exclusivamente de una élite de aristócratas y adinerados arqueólogos europeos y norteamericanos, financiados por grandes instituciones museísticas o sociedades científicas, va cambiando paulatinamente hacia una mayor implicación por parte de los Estados poseedores de los bienes arqueológicos.

En 1967, en la ciudad de Quito, tuvo lugar una reunión enmarcada en ámbito americano que dio lugar al documento conocido como Carta de Quito donde en su introducción se dejó claro que:

Las recomendaciones del presente informe van dirigidas en ese sentido y se ciñen específicamente, a la adecuada conservación y utilización de los monumentos y lugares de interés arqueológico, histórico y artístico, de conformidad con lo que se dispone en el Capítulo $\mathrm{V}$ Esfuerzos Multinacionales Literal d) de la Declaración de Presidentes de América. (INCP 2007:416)

Aquí se institucionaliza que lo esencial para la consideración de un monumento como cultural es la huella del hombre y su función social. De ahí que la Carta se constituya en un instrumento de Solución Conciliatoria entre el PA y el desarrollo económico que desde finales de la década de los sesenta se estaba produciendo especialmente en América del Sur.

En 1990 tuvo lugar en la ciudad suiza de Lausana y promovida por ICOMOS, una reunión que dio lugar a la Carta Internacional 
para la Gestión del Patrimonio Arqueológico. Aquí se define el PA como:

El "patrimonio arqueológico" representa la parte de nuestro patrimonio material para la cual los métodos de la arqueología nos proporcionan la información básica. Engloba todas las huellas de la existencia del hombre y se refiere a los lugares donde se ha practicado cualquier tipo de actividad humana, a las estructuras y los vestigios abandonados de cualquier índole, tanto en la superficie, como enterrados, o bajo las aguas, así como al material relacionado con los mismos (art. 1). (INCP 2007:157-158)

En esta definición, el concepto de lo material está presente a la vez que susceptible de ser estudiado bajo el método arqueológico, desterrando el criterio estilístico (artístico) y dando mayor importancia a la contextualización de los artefactos como producto de la actividad humana. Habla también de la frágil naturaleza y de los constantes peligros a los que está sujeto, proponiendo su incorporación a las políticas de planificación administrativa. Subraya el carácter de bien colectivo y la implicación que la comunidad debe tener no solo en su protección, sino también en su conservación y difusión.

Vemos pues que los cuatro pilares del Patrimonio Cultural comienzan a vislumbrarse en relación con el PA, esto es: el conocimiento, la investigación, la protección y la difusión y señala la dignificación de la figura del arqueólogo como técnico especialista, olvidando el concepto de principios del siglo XX de aventurero romántico descubridor de tesoros señalando en su artículo 8 :

Para asegurar la buena gestión del patrimonio arqueológico, resulta esencial recurrir al dominio de numerosas disciplinas en un alto grado académico y científico. $\mathrm{La}$ formación de un número suficiente de profesionales cualificados en los ámbitos de competencia que nos ocupan debe ser un objetivo importante de la política de educación de cada país. La necesidad de formar expertos en unos campos del saber altamente especializados hace preciso recurrir a la cooperación internacional. La formación arqueológica universitaria debe tener en cuenta en sus programas el cambio operado en las políticas de conservación, menos preocupadas por las excavaciones que por la conservación "in situ". Igualmente debe tomarse en cuenta el hecho de que el estudio de la historia de los pueblos indígenas es tan importante para conservar y comprender el patrimonio arqueológico como el de los monumentos y sitios considerados hasta ahora como los de mayor prestigio. (INCP 2007:160-161)

Aunque sin sustraerse a un cierto sesgo colonialista al hacer referencia en la parte final del artículo a la historia de los "pueblos indígenas" en contraposición con la arqueología europea más centrada en los monumentos, es cierto que avanza ostensiblemente en el planteamiento objetivo de buscar un consenso a la hora de afrontar un PA común. Por último, la Carta hace un llamamiento a la necesidad de la Cooperación Internacional al dotar al PA de valor universal producto del conjunto de la humanidad en su artículo final.

Dos años más tarde, el 16 de enero de 1992 en Malta y aunque referido al ámbito europeo, se publicó el Convenio Europeo sobre la Protección del Patrimonio Arqueológico donde se define el PA como:

Artículo $1^{\circ} 1$. El objetivo del presente Convenio es proteger el patrimonio arqueológico por su carácter de fuente de la memoria colectiva europea e instrumento para el estudio histórico y científico. 2. A este fin se considerarán elementos del patrimonio arqueológico todos los restos y objetos y cualquier otra huella dejada por la humanidad en épocas pasadas que cumplan los siguientes requisitos: a) Que su conservación y estu- 
dio ayuden a reconstruir la historia de la humanidad y su relación con el entorno natural. b) Que las principales fuentes de información sobre dichos restos $\mathrm{y}$ huellas sean la realización de excavaciones $\mathrm{o}$ descubrimientos $\mathrm{y}$ otros métodos de investigación de la humanidad y su entorno. c) Que estén localizados dentro del territorio de las Partes. 3. El patrimonio arqueológico incluirá estructuras, construcciones, grupos de edificios, obras de ingeniería civil, objetos transportables y monumentos de cualquier otro tipo, así como su contexto, sea sobre tierra o bajo el agua. (Convenio Europeo sobre Protección del Patrimonio Arqueológico. La Valetta, Malta, 16.01.1992)

Bastante innovador al considerar al PA como fuente de la memoria colectiva, lo concibe como un instrumento auxiliar para construir una historia común y propone una serie de requisitos que deberán cumplir todos los bienes susceptibles de formar parte de esta categoría: su utilidad en la reconstrucción del pasado, el método de excavación y su localización dentro del territorio de los firmantes. Sin embargo, en el apartado tercero, nombrando distintas categorías hace una referencia clara a la contextualización y esta es una cuestión que me parece verdaderamente trascendental.

Por vez primera en un documento de carácter internacional, se nombra el contexto y no el bien mueble o inmueble. Así, el PA, según la Declaración de La Valetta, debe estar formado no solo por un conjunto de bienes (muebles e inmuebles) independientemente de la procedencia y estudiados con metodología científica, sino que a este concepto se le suma el de su contexto (sea estratigráfico, territorial, etc).

Consideraciones sobre el Patrimonio Arqueológico en el ámbito Internacional Vistos los anteriores documentos, cabe hacernos una pregunta: ¿Realmente tenemos claro qué es el Patrimonio Arqueológico? ¿Existe un Patrimonio Arqueológico mundial? Quizás, si buscáramos en sus orígenes podríamos aproximarnos a la cuestión con mayor perspectiva.

Tradicionalmente el término Patrimonio proviene del latino patrimonium que ha sido definido como el conjunto de bienes heredados de los antepasados. Si bien esta definición puede valer a título individual (una herencia, por ejemplo), a nivel comunitario debemos entenderlo como un conjunto de bienes y costumbres que legamos y transmitimos porque reconocemos en ellos valores que son innatos a nuestra comunidad. Se trataría de una construcción social de valores culturales. Por tanto, nuestro patrimonio no nos pertenece de manera individual sino colectiva. Sin embargo, este es un concepto eurocentrista pues en muchas sociedades el concepto de herencia común es diametralmente distinto.

La UNESCO, según la Declaración de México sobre las Políticas Culturales celebrada entre el 26 de julio y el 6 de agosto de 1982 en D. F., definió el concepto de Patrimonio Cultural como:

El Patrimonio Cultural de un pueblo comprende las obras de sus artistas, arquitectos, músicos, escritores y sabios, así como las creaciones anónimas, surgidas del alma popular, y el conjunto de valores que dan sentido a la vida, es decir, las obras materiales y no materiales que expresan la creatividad de ese pueblo; la lengua, los ritos, las creencias, los lugares y monumentos históricos, la literatura, las obras de arte y los archivos y bibliotecas. (INCP 2007:273)

Una definición amplia que, sin embargo, ha debido de recorrer un largo camino para poder enunciarse.

Quizá podríamos evocar el fenómeno del coleccionismo como punto de partida, aun- 
que este hecho estaría más bien ligado a la adquisición de bienes (e incluso al origen del museo) y no tanto al concepto de Patrimonio. Como señalan todos los documentos internacionales, así como las legislaciones nacionales, el concepto de Patrimonio va indisolublemente ligado al de memoria histórica. Se trata de valorar un vínculo existente entre el presente y las comunidades que han vivido en el pasado.

Un ejemplo de esto lo podemos recrear en el ambiente vivido en la Roma del Renacimiento cuando gracias a la labor de algunos papas (en especial Martín en 1420) (Choay 2007:16) que pretendieron recuperar la grandeza de la ciudad tomando como modelo la Roma imperial (figura 2), desaparecida hacía mil años pero que conservaba un gran número de monumentos, restaurando y conservando una importante parte de ellos. Pio II, en 1462 por medio de la bula Cum Almam Nostram Urbem, instaurará el primer intento de regulación del patrimonio arqueológico ya que establecerá que dichos monumentos son testimonios irreemplazables del pasado y que deberán ser conservados, contemplando incluso un sistema impositivo de multas en caso de destrucción (Hoz 2009:3).

Sin embargo, el actual concepto de Patrimonio aparece ligado a la Ilustración, ya que serán precisamente los ilustrados quienes utilicen la historia para señalar el pasado común de los pueblos. Surgirá así el concepto arqueológico de monumento antiguo (García Cuetos 2012:21) para definir principalmente los edificios de la Antigüedad. No debemos olvidar que será durante el siglo XVIII cuando nazca la ciencia arqueológica merced a las excavaciones patrocinadas por el futuro rey Carlos III en Herculano y Pompeya (fi-

Figura 2.- Roma (Italia). Foro republicano

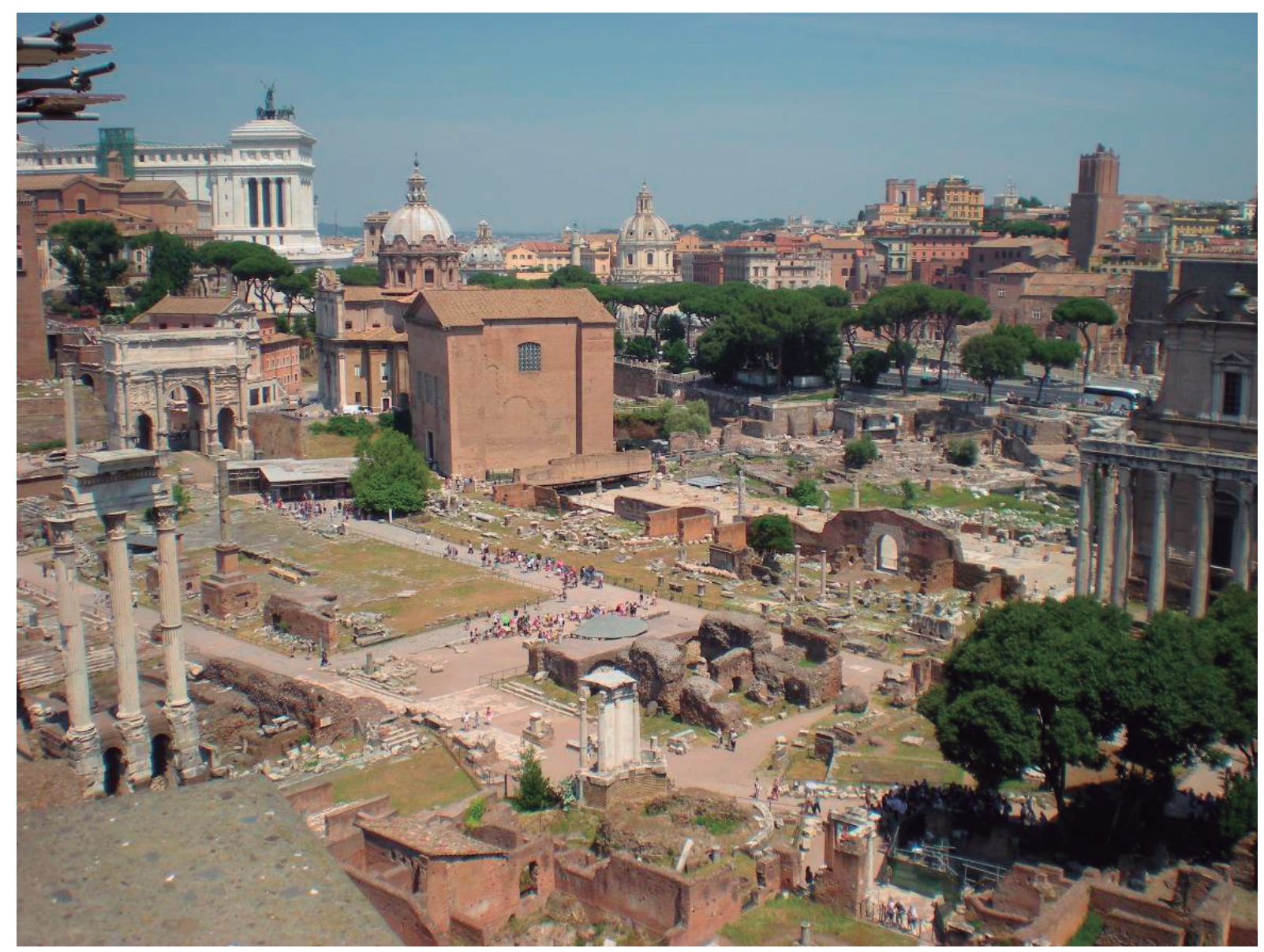

Fuente: Elaboración propia

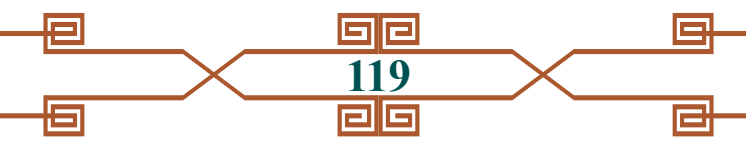


gura 3) aunque motivados más hacia el coleccionismo de obras artísticas.

Con la Revolución Francesa y el nuevo concepto de Estado, va tomando cuerpo la idea de que los monumentos pertenecen a la comunidad y no al rey o al clero y que, al ser símbolos de la patria, hay que conservarlos y legarlos a las generaciones futuras. Además, la igualdad instaurada como valor primordial por la Revolución, hará que todos tengan derecho a disfrutar del patrimonio monumental.

Con el siglo XIX, los nacionalismos no harán sino potenciar los valores de los monumentos históricos como parte importante de un pasado común y será ahora cuando se hagan sistematizaciones y estudios importantes. No obstante, no será hasta después de la Primera Guerra Mundial cuando el concepto de Patrimonio Cultural (y el Patrimonio Arqueológico con él) traspasará la frontera de lo nacional para hacerse universal. Fruto de este estado será la comentada Carta de Atenas de 1931 donde se tratará del PA por vez primera como patrimonio que debe interesar a todos los países para su conservación.

Es durante finales del XIX y la primera mitad del siglo XX cuando el concepto de PA irá irremediablemente ligado al descubrimiento de nuevas civilizaciones (continente americano, Próximo Oriente, etc.) donde los valores estéticos y artísticos primarán por encima de otros. Así, surgirán los conceptos de objetos artísticos, de bellas artes, tesoros artísticos, etc que se verán refrendados en cuerpos legales los cuales adoptarán similar nomenclatura (un ejemplo, la española Ley del Patrimonio Artístico Nacional de 1933 o la creación en 1905 de la Comisaría General de Bellas Artes y Monumentos).

No será hasta 1954, tras los devastadores efectos provocados por la Segunda Guerra Mundial, cuando se acuñe el concepto de Bien Cultural que englobará toda esta amal-

Figura 3.- Pompeya (Italia). Foro

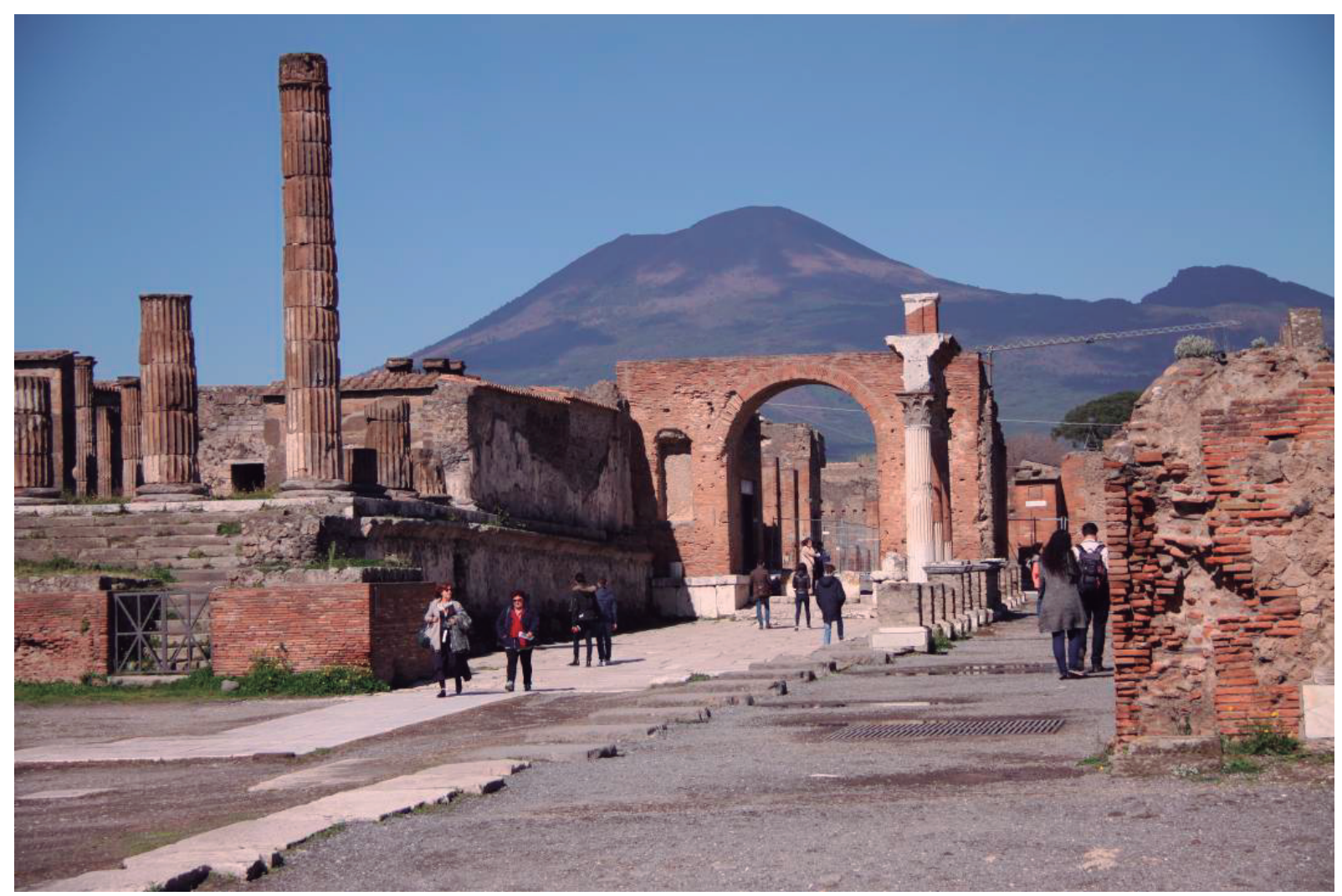

Fuente: Elaboración propia

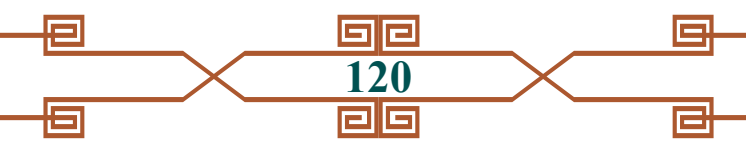


gama de nombres.

Efectivamente, el 14 de mayo de ese año en la ciudad holandesa de La Haya, se elaboró un protocolo mediante el cual se acuñaba el término de Bien Cultural y se prohibía la exportación de los mismos mientras un territorio fuese ocupado en caso de guerra, su confiscación como pago por reparaciones de guerra y la exigencia de entrega de los bienes culturales en caso de sustracción por un Estado.

Esta humanización del derecho patrimonial supone que sea considerado como un derecho fundamental por lo que atentar contra el patrimonio histórico y arqueológico de un pueblo es atentar contra ese pueblo. De ahí la necesidad de esclarecer los términos adecuadamente.

\section{CONCLUSIONES}

Vistas las líneas anteriores, podemos tener claras varias cuestiones: en primer lugar, que según la práctica totalidad de los documentos internacionales referidos al PA, para su definición se utilizan dos conceptos que se repiten sistemáticamente: es un patrimonio material y es un patrimonio histórico sujeto a una especial metodología de estudio.

Así, para que un objeto sea adscrito al PA necesariamente debe ser un objeto físico, material y estar dotado de un valor histórico, que no artístico o estilístico. La principal cualidad del bien es su historicidad sea esta relevante o no.

Por tanto, para la comunidad internacional, cualquier objeto material con valor histórico entraría a formar parte del PA. Sin embargo, necesitamos de una nueva variable y es la de la metodología con la que se estudia. Lo que dota de especificidad al PA es su método de estudio: el método arqueológico. Así, cualquier objeto histórico no necesariamente debe formar parte del PA y solamente será considerado como tal el que sea susceptible de ser estudiado con metodología arqueológica.

Dicho de este modo, parece que el PA queda vacío de contenido ya que no debemos olvidar que este conjunto de bienes cumple una acción social que ha sido revalorizada a lo largo de los últimos tres siglos como hemos visto en las páginas anteriores.

No obstante, es evidente que dentro del concepto general de Patrimonio Histórico (o Cultural que me parece más apropiado), el PA goza de poca popularidad. Una catedral o un monumento en una plaza de cualquier ciudad será mucho más valorado por el conjunto de la sociedad que un yacimiento arqueológico; y esto sucede porque en el primero de los casos, la catedral está viva, se sigue utilizando como edificio de culto; o el monumento en la plaza reseña un hecho histórico recordado. Sin embargo, la visión que la sociedad tiene del PA es la de un conjunto de bienes olvidados, cuya función y uso pasó hace mucho tiempo. Por no hablar del concepto elitista y científico del arqueólogo.

¿Por qué ocurre esto? Pues porque salvo casos verdaderamente espectaculares, el PA necesita de un intérprete que valore, contextualice y difunda dichos bienes. En una sociedad donde el PA apenas tiene cabida en los planes de estudio ya que esta materia se trata generalmente bajo conceptos de Historia del Arte, los bienes arqueológicos deben ser valorados por la sociedad y eso, hoy por hoy, es difícil de conseguir. Incluso no es de extrañar que la propia sociedad a veces perciba estos bienes como un freno al progreso al considerarlos poco útiles ya que pueden condicionar el desarrollo de un proyecto constructivo, por ejemplo una carretera, un viaducto o un hospital.

Hasta mediados del siglo XX, el único valor que los bienes integrantes del PA tenían era el de objetos curiosos o todo lo más artísticos que daban prestigio a sus propietarios, por tanto, interesaba a una parte de la sociedad: la que disponía de una sensibilidad hacia estos objetos artísticos. Lo mismo 
ocurría a nivel de Estados; así los grandes países europeos se enzarzaron en una carrera por conseguir el mayor número de objetos artísticos de territorios cuyas sociedades no disponían de clases sociales con estos gustos refinados. Me refiero al llamado fenómeno del elguinismo.

Hoy día, la concepción como bien social impide que se produzcan tales hechos y el PA viene considerado como un elemento más de la identidad cultural de un pueblo por lo que se convierte en parte de la memoria colectiva del mismo (Baldeón 2002:24).

Que el PA va indisolublemente asociado a la metodología arqueológica ha quedado demostrado en las líneas anteriores. Pero no debemos olvidar que la excavación es un método destructivo, que simplemente reemplaza un bien a costa de otro. Así, para conocer y disfrutar de un objeto arqueológico, necesariamente se ha tenido que destruir su contexto estratigráfico de ahí la importancia de la prevención a la hora de intervenir sobre el PA.

Es necesario, por tanto, inventariar para conocer y solo después de estos dos pasos, podrá plantearse la ejecución de un proyecto si éste va a ser comunicado por medio de su publicación y puesta en valor. Así convertiremos el PA en un valor social libre de prejuicios elitistas y accesible a toda la sociedad, su verdadera propietaria.

Conocer es fundamental y para eso hace falta una planificación. Es lo que conocemos como Arqueología Preventiva y ésta no puede sino estar en manos de las administraciones públicas que tienen el deber de transmitir y conservar para futuras generaciones el PA. Así se desprende de la mayoría de documentos que hemos analizado anteriormente, como la Carta de Lausana de 1990.

Para conocer hay que actuar de manera no traumática en el yacimiento. La Administración se ha dotado así de unidades especializadas como Institutos (el Instituto Nacional de Patrimonio Cultural de Ecuador sería un ejemplo), que cuentan con personal técnico adscrito y que llevan a cabo una tarea de planificación de actuaciones arqueológicas por medio de instrumentos específicos como las Cartas de Riesgo Arqueológico (en España, por ejemplo) o planes directores en Conjuntos y Enclaves arqueológicos.

Una planificación técnica es fundamental para tener un conocimiento efectivo del PA. Sin embargo, éste nos es desconocido hasta que no se muestra y solo podemos movernos mediante indicios y en el terreno de la hipótesis. Como instrumento fundamental para el conocimiento del PA contamos con la prospección (en sus diversas facetas) que puede acercarnos al yacimiento de una manera controlada.

Sin embargo, el conocimiento no basta para conseguir la salvaguarda del PA. Así, la administración ha de dotarse de instrumentos legislativos que regulen las actividades arqueológicas en todos sus aspectos, desde la concesión de autorizaciones hasta el traslado y exposición de los bienes recuperados en lugares acondicionados para ellos además de evaluar si procede o no a su conservación o traslado. La mayoría de Estados cuentan con leyes que regulan de una u otra manera el PA.

Concluyendo, creo que es hora de hacernos la gran pregunta: ¿Y para qué sirve todo esto? Vimos en párrafos anteriores que al ser un bien tan selectivo y a veces carente de todo componente estético, el PA no suele ser valorado convenientemente por la sociedad. Es por esto que tanto los profesionales de la arqueología como las administraciones involucradas en su gestión, así como entidades afines como universidades, instituciones museísticas, fundaciones culturales, etc., deben hacer un trabajo de pedagogía social de cara a mostrar lo que significa para una sociedad conocer y salvaguardar su PA.

Historia vero testis temporum, lux veritatis, vita memoriae, magistra vitae (la historia es 
el verdadero testigo de los tiempos, la verdadera luz, memoria y maestra de la vida). Esta máxima de Marco Tulio Cicerón (De Oratore, II, 36) creo que cobra actualidad y es acorde con los planteamientos aquí expuestos.

\section{REFERENCIAS BIBLIOGRÁFICAS}

Baldeón, A. (2002). El Patrimonio Arqueológico. Memoria para el futuro. XV Congreso de Estudios Vascos. San Sebastián. pp. 21-27

Choay, F. (2007). Alegoría del Patrimonio. Barcelona.

De Hoz, J. (2009). La conservación del Patrimonio histórico y su contribución al desarrollo social y económico. Axa. Una Revista de Arte y Arquitectura. Univ. Alfonso X el Sabio: Madrid. pp. 1-15.

García Cuetos, Ma P. (2012). El Patrimonio Cultural. Conceptos Básicos. Zaragoza.

Querol, Ma A. y Martínez Díaz, B. (1996). El Patrimonio Arqueológico en la normativa internacional. Complutum Extra 6 (II). Univ. Complutense: Madrid. pp. 295-306.

Querol, Ma A. (2010). Manual de Gestión del Patrimonio Cultural. Madrid.

INCP (2007): Documentos Fundamentales para el Patrimonio Cultural. Textos internacionales para su recuperación, repatriación, conservación, protección y difusión. Instituto Nacional de Cultura del Perú. Lima.

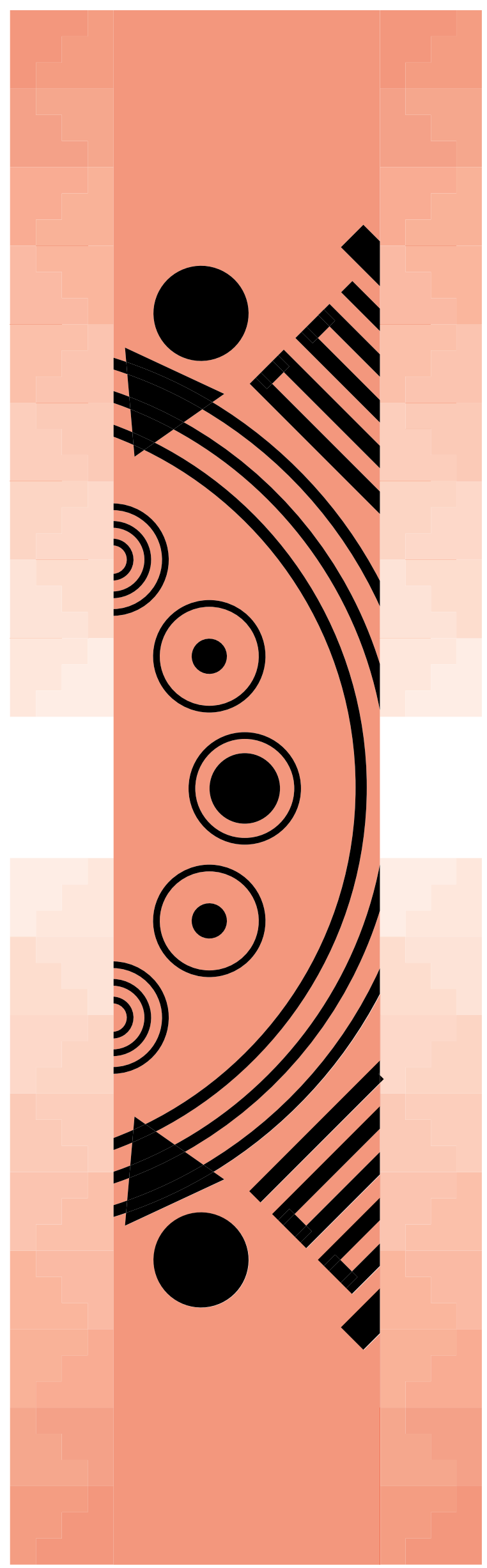

$\underbrace{\frac{\text { 回 }}{123}}_{\text {回回 }}>\underbrace{\text { 回 }}_{\text {回 }}$

